\title{
Study of sintering temperature on the structure of silicon carbide membrane
}

\author{
A. Sadighzadeh $\cdot$ Sh. Mashayekhan • \\ B. Nedaie - A. H. Ghorashi
}

Received: 18 April 2013/Accepted: 15 July 2014/Published online: 11 September 2014

(C) The Author(s) 2014. This article is published with open access at Springerlink.com

\begin{abstract}
Study of the microstructure of silicon carbide (SiC) membrane as a function of sintering temperature and the percentage amount of additive kaolin is the outcome of the experimental fabrications presented in this paper. The SEM micrographs are used to investigate the impact of above parameters on the porosity of membrane. The experimental results show that the rise in the temperature causes more sintering of powder particles, growing granules, augmentation of the number of pores and consequently increasing the total porosity of membrane. Using $\mathrm{XRD}$ analyses, it is found that $\mathrm{SiC}$ amorphous phase is highly sensitive to the temperature and its crystallization physically grows with temperature increase.
\end{abstract}

Keywords Ceramic membrane - Sintering temperature . Additive kaolin - Granules and porosity

\section{Introduction}

Different types of air treatment methods are used in industries, depending on; type of pollutants, economic factors and their impacts on environment.

A. Sadighzadeh $(\bowtie) \cdot$ B. Nedaie · A. H. Ghorashi

Plasma Physics and Nuclear Fusion Faculty, Nuclear Science and Technology Research Institute, AEOI, Tehran, Iran e-mail: asadigzadeh@aeoi.org.ir

Sh. Mashayekhan

Department of Physics North Branch, Islamic Azad University, Tehran, Iran

B. Nedaie

Department of Physics Ardabil Branch, Islamic Azad University, Ardabil, Iran
The conventional air treatment systems include; precipitators, cyclones, wet scrubbers, fiber filters, ceramic filters and so on [1-4].

Ceramic filters are resistant against solvent and high temperatures [5]. These filters have good aerosol particle removal efficiency. Ceramic filters have a large use in industries particularly in the corrosive, high-temperature and high-pressure environment. These filters are recoverable. It is also possible to improve the filtration quality of these filters by ameliorating the holes and consequently the porosity of ceramic filters results in decreasing the pressure drop and increasing the separation efficiency [6-8]. These filters offer a unique method in the treatment of effluents in industries. The ceramic filters can also be used for gaseous separation, especially for isotope separations of an element in the nuclear industries $[9,10]$.

In this research, different samples of silicon carbide membranes were fabricated using sintering method. The 500-6,000 magnification micrographs; taken from the samples to study the microstructures, showed that by increasing the temperature we can gain larger holes, more outlet holes and consequently increase in porosity, reduction of pressure drop and hence we can achieve ceramic membranes with improved quality.

\section{Samples fabrication}

In this study, the sintering method was used for fabrication of silicon carbide membrane. Silicon carbide powder and polyvinyl alcohol (PVA) are used, respectively, as a base and retentive. Kaolin was served as a sintering aid [11, 12].

Different samples were made by mixing the $\mathrm{SiC}$ powder together with the average particle size of $100 \mu \mathrm{m}$ and kaolin of $8,12,16$ and $20 \%$. Then, $2 \%$ solution of polyvinyl 
Table 1 Specifications of die block

\begin{tabular}{llll}
\hline & $\begin{array}{l}\text { Height } \\
(\mathrm{mm})\end{array}$ & $\begin{array}{l}\text { Inner diameter } \\
(\mathrm{mm})\end{array}$ & $\begin{array}{l}\text { Outer diameter } \\
(\mathrm{mm})\end{array}$ \\
\hline Matrix & 95 & 56 & 89 \\
Small pines & 13 & 0 & 55.5 \\
Big punch & 54 & 0 & 55.5 \\
\hline
\end{tabular}

alcohol was used as glue in the crude membrane. To do this, the material is added to the $\mathrm{SiC}$ powder, which is homogeneously mixed with kaolin. For this purpose, an ingot mold of SPK steel was made along with two rods and a die block with specifications as per mentioned in Table 1 .

To make the samples of crude membrane, firstly, the die walls, surfaces of punch and the die are greased with Stark Oil. Secondly, the homogeneous mixture is poured into the die. Then, 4 tons of pressure is gently applied on the die. After a few seconds, the pressure is slowly lowered and the crude membrane is removed from the die. It is to be noted that the pressure is slowly lowered to prevent incarnating the air mass among the particles, which causes some cracks on the samples.

In this way, some disk-shaped samples of silicon carbide with $56 \mathrm{~mm}$ diameter and $1.2 \mathrm{~mm}$ thickness and four types of membrane with the additive percentage of $8,12,16$ and 20 were produced. From each sample, 4 items and 16 items altogether were made to perform different tests. The crude samples are then sintered in the oven at 1,400, 1,425, 1,450 and $1,475{ }^{\circ} \mathrm{C}$ with track temperature of $50{ }^{\circ} \mathrm{C}$ per minute for raising and lowering the temperature at the range of ambient temperature of $1,000{ }^{\circ} \mathrm{C}$ as well as with track temperature of $20{ }^{\circ} \mathrm{C}$ per minute at the ambient temperature range of above $1,000{ }^{\circ} \mathrm{C}$. At first, the initial four samples including $8 \%$ kaolin were sintered at $1,400-1,475{ }^{\circ} \mathrm{C}$.

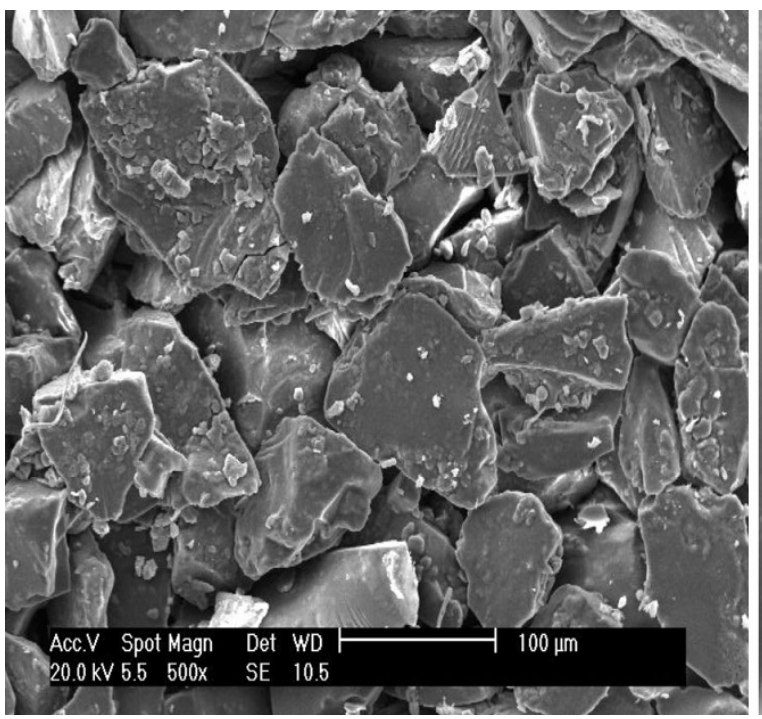

Samples with the additives of 12,16 and $20 \%$ were also processed in the same way. To sinter the samples, the period of placing them at the mentioned temperature is $24 \mathrm{~h}$ and it was observed that such samples have a macrostructure without any exterior deficiency and a good mechanical resistance. The microstructures of membranes were studied, using the electron microscope "SEM Phillips XL30".

It is necessary to accentuate that the samples prepared by sintering method in this research have macrostructures without any exterior deficiency and possess a good mechanical resistance.

\section{Results and observations}

To investigate the microstructures of the samples, their 500 and 6,000 magnification micrographs were supplied.

Using the pictures with granules magnification size of 500 ratios, the distance between them and the porosity of the samples were studied. The pictures with the magnification ratio of 6,000 were supplied to study the influence of additives on the structure of ceramics. To study the microstructure of the samples, 64 micrographs were prepared. The study of the prepared samples shows that ceramics are formed from granules with dimensions of $50-100 \mu \mathrm{m}$. For instance, in Figs. 1, 2, 3 and 4, the micrographs associated with $8 \%$ sintered samples at temperatures of 1,400, 1,425, 1,450 and $1,475{ }^{\circ} \mathrm{C}$ are, respectively, depicted. These micrographs show that the temperature increase will cause; the particles sinter well, holes become larger, numbers of outlet holes increase and hence the porosity will also increase.

As it is depicted in Figs. 1, 2, 3 and 4, all graphs of the prepared samples with magnification ratio of 500 are porous and larger masses (granules) are created due to joining

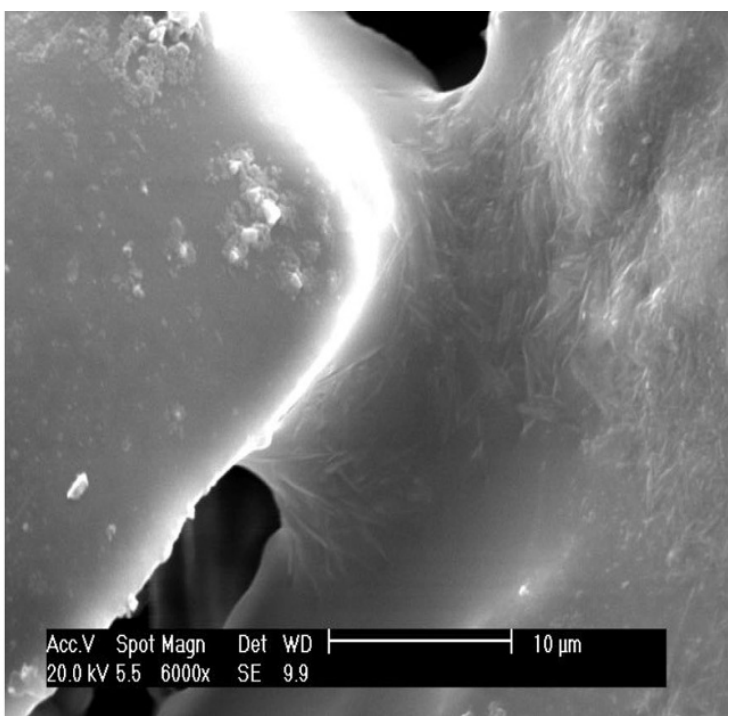

Fig. 1 Micrograph of sample 1 with 500 and 6,000 magnifications 

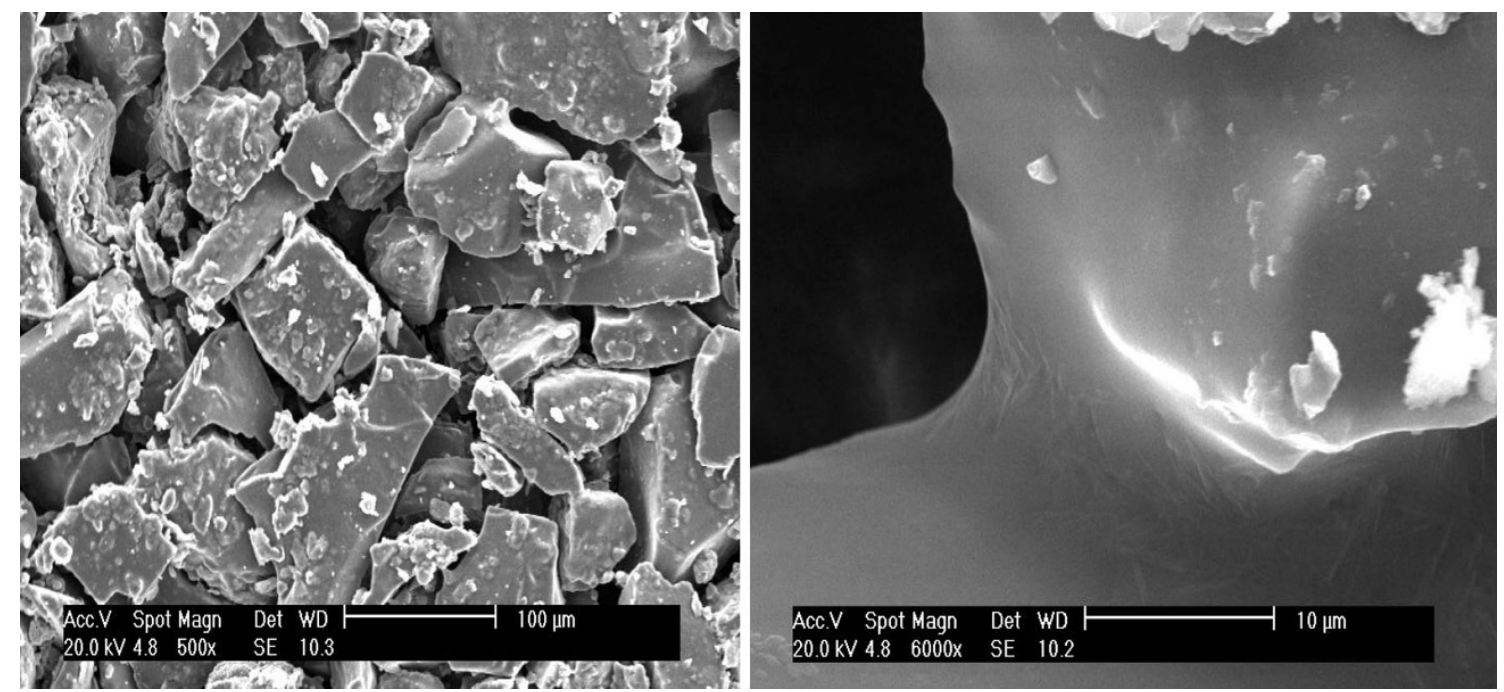

Fig. 2 Micrograph of sample 2 with 500 and 6,000 magnifications
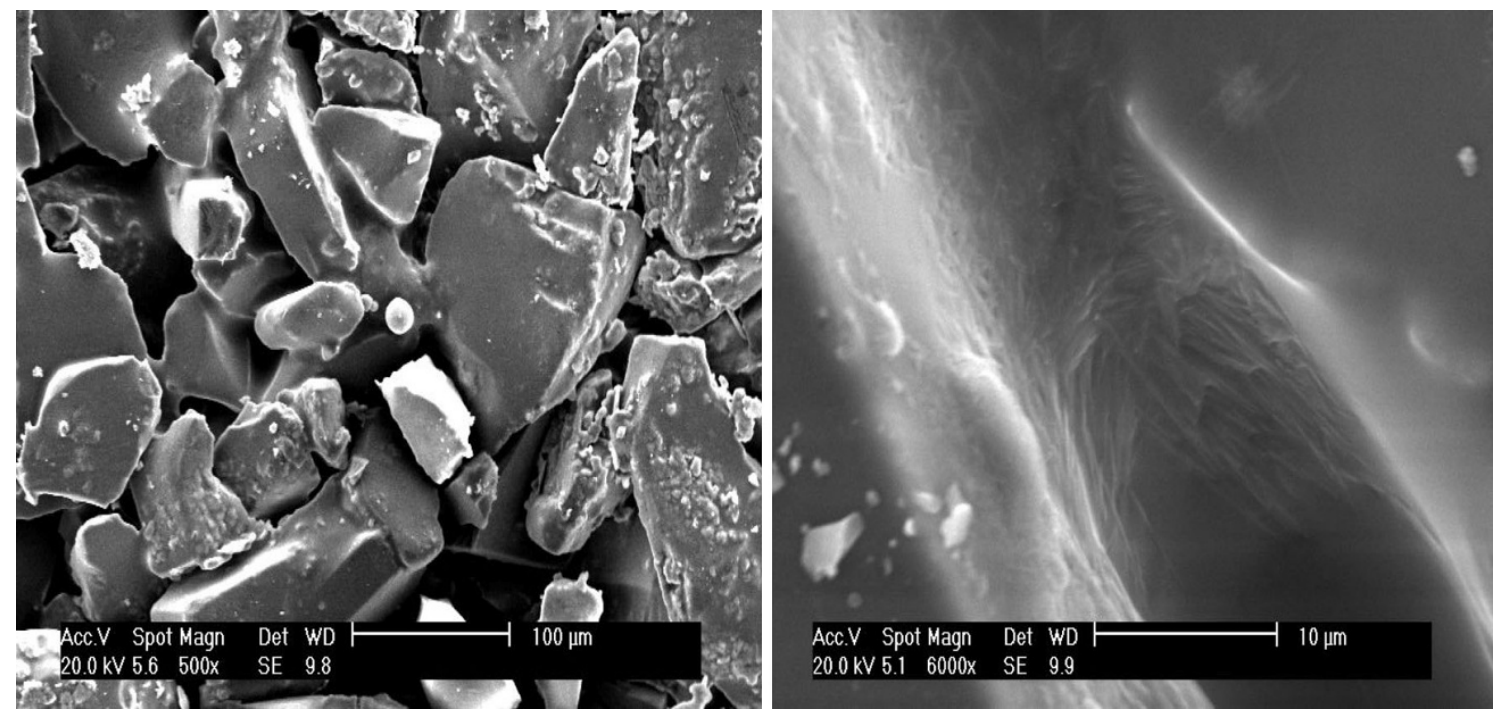

Fig. 3 Micrograph of sample 3 with 500 and 6,000 magnifications

of powder particles together. After sintering of the particles, more holes are observed and since the holes are smaller, the porosity decreases too. The study of pictures shows that the average size of granules and the holes are about 100 and $30 \mu \mathrm{m}$, respectively.

In figures with magnification ratio of 6,000 , the filaments with dimensions of several microns are observed. Theses filaments indicate the formation of mullite phase in the samples. In fact, in the process of sintering, kaolin added to carbide silicone has turned into mullite and cristobalite phase. It is to be noticed that cristobalite is a form of $\mathrm{SiO}_{2}$ and mullite is a form of $\mathrm{SiO}_{2}$ and $\mathrm{I}_{2} \mathrm{O}_{3}$.

In this research work, the rate of membrane porosity using the method of pressure drop measurement based on debit was investigated.
An inorganic membrane performance is remarkably dependent on its micron structure such as; the holes size, their size distribution, porosity and the number of outlet holes [13-16].

In this research, to ensure the effect of temperature on the ceramic membranes, their pressure drop was studied as a function of gas transmission debit [17]. For example, Fig. 5 shows the pressure drop charts $(\Delta p)$ at debit $(Q)$ for $8-20 \%$ samples, which have sintered at $1,475^{\circ} \mathrm{C}$.

As shown in figures, all the charts are linear. Comparing the charts, one can conclude that pressure drop at the samples with $\mathrm{SiC}$ membrane is directly related to additive percentage rate and therefore the rate of samples porosity is inversely related to the percentage of additives. 

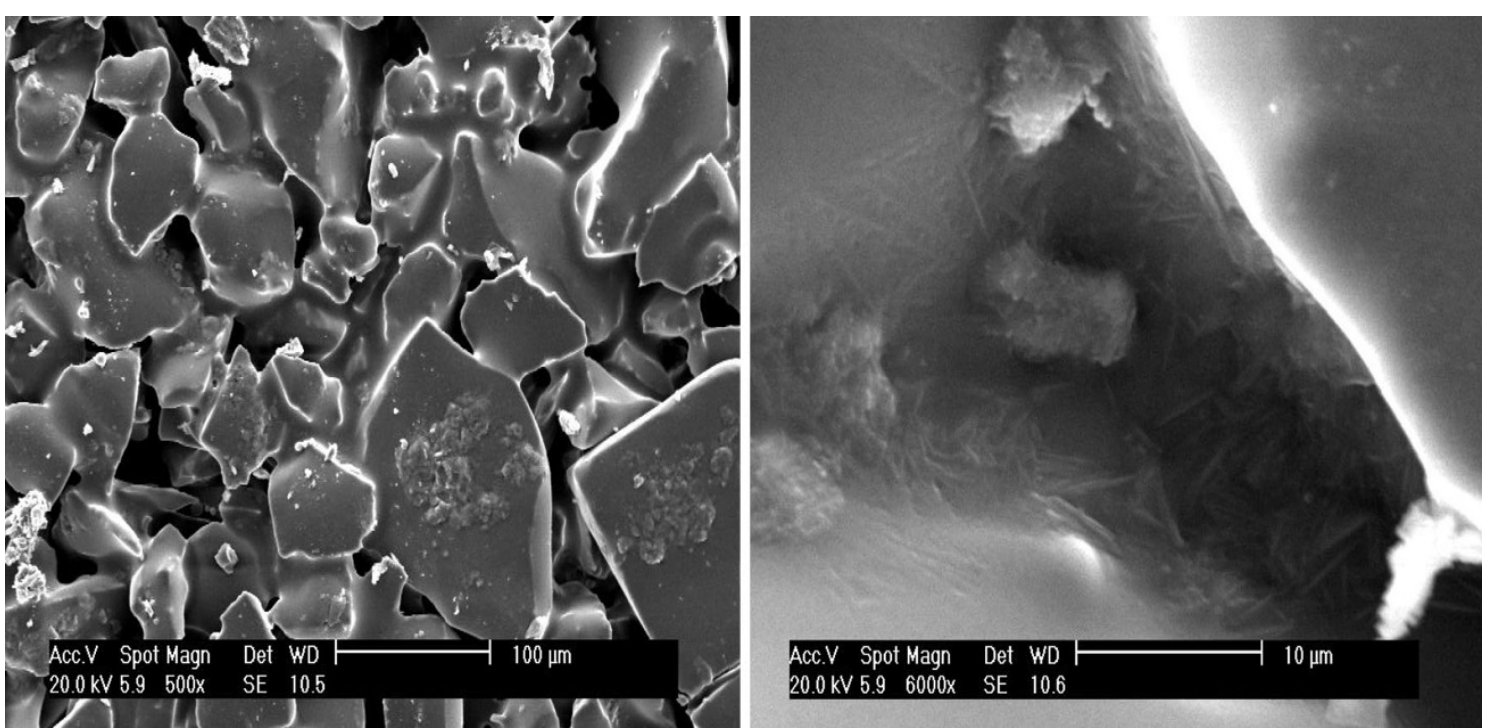

Fig. 4 Micrograph of sample 4 with 500 and 6,000 magnifications

Fig. 5 Flowcharts of pressure drop in Sintering at $1,475{ }^{\circ} \mathrm{C}$

Fig. 6 Flowcharts of pressure drops for samples with $8 \%$ additive
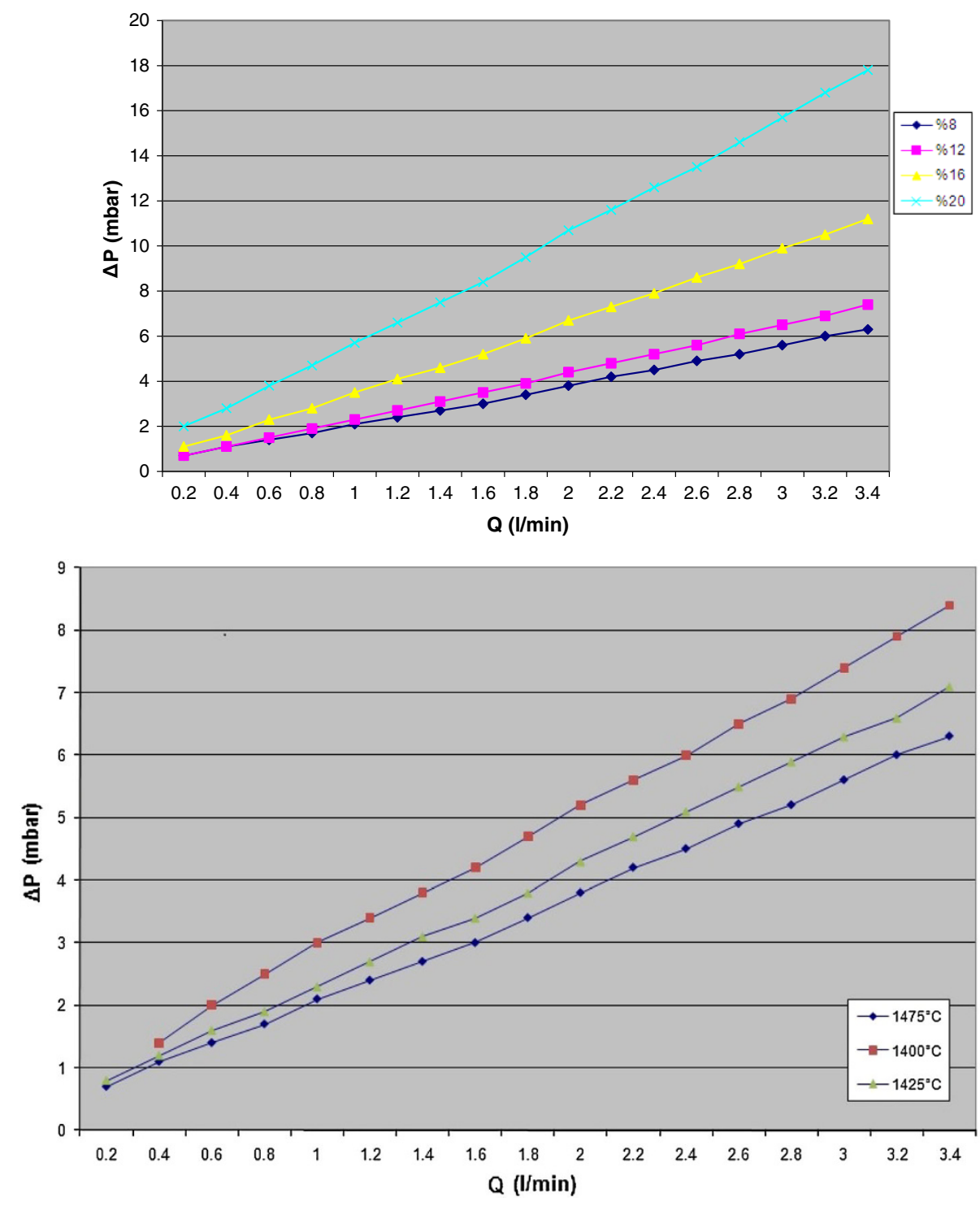
Debit charts at pressure drop for all the samples were investigated, considering the parameter of additive percentage remains constant and the temperature parameter being variable. For instance, Fig. 6 shows the pressure drop charts $(\Delta p)$ at debit $(Q)$ for $8 \%$ samples, which have sintered at $1,400-1,475^{\circ} \mathrm{C}$.

Results of this study showed that in samples with specific additive percentage, pressure drop has a reverse relationship with the increase of sintering temperature. Hence, the porosity has a direct relationship with temperature increase. For instance, in $3 \mathrm{l} / \mathrm{min}$ debit, the pressure drop of ceramic membranes sintered at temperatures of 1,425 and $1,475{ }^{\circ} \mathrm{C}$ equals to 6.2 and 5.7 millibar, respectively.

\section{Conclusion}

Study of the sintering temperature effects on the structures of ceramic membranes indicates that at high temperatures, the form of granules and their sharp angles melt away. On the other hand, the numbers of outlet holes increase. The above changes cause the reduction of pressure drop and lead to quality improvements of ceramic membranes. In addition, the pressure drop of the sintered samples increases with increasing the amount of additives at original composition and the porosity decreases.

Acknowledgments This research was carried out with the support of JABER Lab.-AEOI and Islamic Azad University-Northern Branch.

Open Access This article is distributed under the terms of the Creative Commons Attribution License which permits any use, distribution, and reproduction in any medium, provided the original author(s) and the source are credited.

\section{References}

1. Das, N., Maiti, H.S.: Formation of pore structure in tape-cast alumina membranes-effects of binder content and firing temperature. Central Class and Ceramic Research Institute. 140:205-212 (1998)

2. Venkataraman, K., Choat, W.T., Torret, E.R., Tusung, R.D.: characterization study of ceramic membranes, a novel technique using a coulter pyrometer. J. Membr. Sci. 39, 259 (1998)

3. Ruiz, J.C., Blanc, P., Prouzet, E., et al.: Solid aerosol removal using ceramic filters. Sep. Purif. Technol. 19(3), 221 (2000)

4. Ruiz, J.C., Balance, Ph, Prouzet, E., Cory, P., Laffont, P., Larbot, A.: Solid aerosol removal using ceramic filters. Sep. Por. Tech 19, 221 (2000)

5. Harper, C.A.: Hand book of ceramic, p 26 (2001)

6. Cheryan, M.: Ultrafiltration and microfiltration handbook, Technomic publishing Co. Inc (1998)

7. Rosenbloom, A.J., Shishkin, Y., Sipe, D.M., et al.: Porous silicon carbide as a membrane for implantable biosensors (2004)

8. Liu, B.Y.H., Rubow K.L.: Proceedings of the fifth world filtration congers nice, 0-8 June 1990, sociate Francaise de filtration, Cachan, vol 3, p 112 (1990)

9. Ishizaki, K., Komarneni, S., Nanko, M.: Porous materials, process and technology, Kluwer Academic publishers (1998)

10. Nanko, M., Ishizaki, K., Fujikawa, T.: Porous ceramic produced by isostatic pressing. J. Am. Ceram. Soc. 77(9), 2437 (1994)

11. Microstructure and fracture of some SiC-based clay bonded hot gas filter materials after exposure to thermal cycling and/or high temperature water vapour (2003)

12. Schwier, G., Teusel, I., Lewis, M., et al.: Characterization of SiC powders and the influence of powder properties on sintering. Pure Appl. Clam. 69(6), 1305 (1997)

13. Hsieh, H.P.: Inorganic membrane for separation and reaction eBook. Elsevier, Alcoa Technical Center (1996)

14. Bhave, R.: Inorganic membrane synthesis characterization and application. Van Nostarnd Reinhold, London (1991)

15. Burggraaf, A.J., Cot, L.: Fundamentals of inorganic membrane science and technology. Elsevier, Amsterdam (1996)

16. Labot, Andre, Fabre, Jean-paul, Guizard, Christian, Cot, Louis: New inorganic ultra-filtration membrane: titania and zircinia membrane. J. Am. Ceram. Soc. 72(2), 257 (1989)

17. Heikkinen, M.S.A., Harley, N.H.: Experimental investigation of sintered porous metal filters. J. Aerosol Sci. 31(6), 721 (2000)

18. Salamone, A.L., Reed, J.E.: Preparation and microscopic analysis of cellulose binder solution, ceramic bulletin, vol. 50, p. 6 (1979)

19. Burggraaf, A.J., Uhlhorn, J.R., Huisisn, M.N.B.J., Keize, K.: Synthesis of ceramic membrane. J. Membr. Sci. 29, 27 (1992) 